\title{
Performance of Heat Pipe Utilized for Atmospheric Air Heating
}

\author{
Mohammed Mansur \\ Mechanical Department, College of Engineering, Jazan University, Jazan, Kingdom of Saudi Arabia \\ Email: Mohmansur123@yahoo.com
}

Received 5 May 2015; accepted 19 August 2015; published 26 August 2015

\begin{abstract}
The objective of the present experimental work is to investigate the performance of a wrapped screen heat pipe for atmospheric air heating to compare with the limits of this pipe. The experiment was conducted using copper pipe material and acetone as working fluid at different vapor temperatures. The testing also consists of a heater, a blower for heat removal (condenser), temperature measuring device, a vapor temperature probe, acetone charging system, and a vacuum pump. The copper outside diameterof the pipe is $0.022 \mathrm{~m}$, with a total length of $0.6 \mathrm{~m}$. The results showed that the pipe wall temperature (Tw) for a wrapped screen heat pipe has a rapid increase and takes $50 \mathrm{~min}$ to reach steady state at $(Q=63 \mathrm{~W})$. The vapour temperature of working fluid increases as the heat load increases at constant air velocity. It was also been found that the range of vapour temperature deceases as the filling ratio increases that means the increasing of the filling ratio results the decrease of the maximum vapour temperature and the variation in the vapour temperature. The best recorded filling ratio is 0.6 which has the lowest vapour temperature at highest heat load. The maximum heat transport limit for this pipe is $80 \mathrm{~W}$ and the maximum temperature difference for air is $5^{\circ} \mathrm{C}$.
\end{abstract}

\section{Keywords}

Performance, Wrapped Screen, Heat Pipe, Acetone, Air Velocity, Heat Load, Filling Ratio, Temperature Difference

\section{Introduction}

Heat pipes have been used in various applications from cooling electronics, energy recovery to enhancing dehumidification in air conditioning. Heat pipes are used for rice drying [1], most rice dryers rely on heating air, then blowing the air through wet rice paddy to evaporate water from the rice. This process requires large amount of energy to supply the heat for water evaporation as well as to heat the air, which is used as the carrier. The performance of traditional dryers depends heavily on ambient conditions, especially ambient relative humidity. On a sunny day, a batch of rice can be dried in six to ten hours. On a rainy day, it could well take three times as long and three times as much the energy. The irony is when you do have the need for drying; the dryers function efficiently at their worst. Dehumidifier heat pipes are used to produce dry air, and a latent heat pump is used to produce low cost heat energy, from the very ambient air. If we can create dry air, we can achieve faster drying 
rates at lower temperatures. It creates dry air out of wet air and uses the heat of condensation of the water vapors as the source of heat. Analytical models [2] are utilized to investigate the thermal performance of rectangular and disk-shaped heat pipes using nanofluids. The liquid pressure, liquid velocity profile, temperature distribution of the heat pipe wall, temperature gradient along the heat pipe, thermal resistance and maximum heat load are obtained for the flat-shaped heat pipes utilizing a nanofluid as the working fluid. The flat-shaped heat pipe's thermal performance using a nanofluid is substantially enhanced compared with one using a regular fluid. The nanoparticles presence within the working fluid results in a decrease in the thermal resistance and an increase in the maximum heat load capacity of the flat-shaped heat pipe. The existence of an optimum nanoparticle concentration level and wick thickness in maximizing the heat removal capability of the flat-shaped heat pipe was established. The thermal design and the experimental testing of a heat pipe (thermosyphon) heat exchanger for a relatively small commercially available mini-drier for recovering heat from the moist waste air stream to preheat the fresh incoming air [3]. The working fluid used was R134a and the correlations are given for the evaporator and condenser inside heat transfer coefficients as well as for the maximum heat transfer rate. The theoretical model and computer simulation program used for the thermal design calculations are described. The validity of the as-designed and manufactured heat exchanger coupled to the drier is experimentally verified. The theoretical model accurately predicted the thermal performance and a significant energy savings and a reasonable payback period was achieved.

An experimental study the behavior of nanofluid to improve the performance of a circular heat pipe [4]. Pure water and $\mathrm{Al}_{2} \mathrm{O}_{3}$-water based nanofluid are used as working fluids. An experimental setup is designed and constructed to study the heat pipe performance under different operating conditions. The effect of filling ratio, volume fraction of nano-particles in the base fluid, and heat input rate on the thermal resistance is investigated. Total thermal resistance of the heat pipe for pure water and $\mathrm{Al}_{2} \mathrm{O}_{3}$-water based nanofluid is also predicted. An experimental correlation is obtained to predict the influence of Prandtl number and dimensionless heat transfer rate, $\mathrm{Kq}$ on thermal resistance. Thermal resistance decreases with increasing $\mathrm{Al}_{2} \mathrm{O}_{3}$-water based nanofluid compared to that of pure water. The experimental data is compared to the available data from previous work. The agreement is found to be fairly good.

The effect of the aspect ratio and filling ratio on the thermal performance of an inclined two-phase closed thermosyphon under normal operating conditions has been investigated experimentally [5]. The experiments were carried out for filling a ratio range of $20 \% \leq$ F.R $\leq 60 \%$ and aspect ratios of 15, 20, and 30 for an inclination angle range of $15^{\circ} \leq \Phi \leq 90^{\circ}$. The thermosyphon was manufactured using a copper tube with an inside and outside diameter of 14 and $16 \mathrm{~mm}$ respectively, and a $1000 \mathrm{~mm}$ length. Distilled water was used as the working fluid. The heat transfer rate, temperature distribution, and condensation heat transfer coefficient of the inclined two-phase closed thermosyphon were measured. The results showed that the maximum thermal performance of the thermosyphon occurred at $60^{\circ}$ for all three aspect ratios and several filling ratios. The thermal performance of the inclined thermosyphon with an inclination angle of $60^{\circ}$ was better for a filling ratio of $45 \%$. It was also found that a higher condensation heat transfer coefficient for all three aspect ratios took place between 30 and 45 degrees. The effects of fill ratio and inclination on the thermal performance of a water filled two-phase closed thermosyphon was investigated [6] at fill ratios between 0.25 and 1.0, angles of inclination between 30 - 90 degrees from the horizontal and evaporator power input from 304 - $830 \mathrm{~W}$. Within the limits of the experimental investigation, it could be concluded that the performance was in dependent of fill ratio and inclination. The mean evaporating and condensing heat transfer coefficients and the relationship between thermosyphon heat transfer and operating temperature difference between evaporator and condenser were determined. Experimental and theoretical research has been carried out to investigate the thermal performance of water to air thermosyphon heat pipe heat exchanger [7]. Many factors affect the thermal performance of the heat pipe heat exchanger including heat input, water temperature and velocity of output air, filling ratio of working fluid and pipe material. Out of these independently controllable process parameters, heat input, water temperature, and air velocity are selected as factors to carryout the experimental works. The experiments are conducted based on three factor five level central composite rotatable designs with full replications technique. A correlation was developed for the effectiveness of heat pipe heat exchanger in terms of heat input, water temperature and velocity of air. The developed mathematical model is helpful in analyzing the performance of heat pipe heat exchanger. An optimization is done using SYSTAT software and the optimum operating parameters are obtained. This paper reports a study on the effect of the heat flux, cooling water flow rate, fill ratio and extra volume on the overall performance of a partially vacuumed thermosyphon. A rig was made from a $1 \mathrm{~m}$ copper tube with an inner and outer 
diameter of 17.5 and $19 \mathrm{~mm}$. The temperatures at different places on the thermosyphon and on the inlet/outlet of the cooling water were measured. It was observed that change in heat flux, fill ratio and employing different extra volumes, has a significant effect on its performance. On the other hand, with changes in the cooling water flow rate the performance of the thermosyphon was altered regarding the trapped air movement. In order to illustrate the effect of the existence of air in deactivating the thermosyphon, the pipe was cooled down by disconnecting the evaporator power input. It was seen that the thermosyphon loses its performance as the trapped gas occupies the whole condenser. The whole study shows that due to the existence of the trapped air, the heat loads can have significant effects on the thermosyphon performance.

A study on the effect of the heat flux, cooling water flow rate, fill ratio and extra volume [8] on the overall performance of a partially vacuumed thermosyphon. A rig was made from a $1 \mathrm{~m}$ copper tube with an inner and outer diameter of 17.5 and $19 \mathrm{~mm}$. The heights of the evaporator, the adiabatic section and the condenser are 40, 20 and $40 \mathrm{~cm}$, respectively. It was observed that change in heat flux, fill ratio and employing different extra volumes, has a significant effect on its performance. The whole study shows that due to the existence of the trapped air, the heat loads can have significant effects on the thermosyphon performance. The application of a heat pipe heat exchanger [9] or a thermosyphon heat exchanger in the conventional air conditioning systems is recommended as an efficient means for energy savings and dehumidification enhancement to maintain acceptable room conditions. An experimental test [10] has been conducted to determine the effect of heat pipe heat exchanges for pre-cooling and re-heating performance of central air-conditioning systems. The objectives of this research project are to investigate the energy recovery efficiency from using the heat pipe heat exchangers air conditioning systems. The annual energy saving by the heat pipe heat exchangers .The effect of energy recovering efficiency is significant.

The experiment studied the effect of heat source temperature, heating section length ratio, cooling air flow rate, liquid filling rate and pipe diameter on the heat transfer performance of the single-loop red copper-water oscillating heat pipe [11]. The results show that increasing heat source temperature or pipe diameter and reducing filling rate can obviously reduce the thermal resistance of the heat pipe; in the air cooling mode, the cooling thermal resistance outside the pipe is affected by both cooling conditions and heat pipe cooling section average temperature; when the heating section is shorter than the cooling section, the heat pipe thermal resistance shows an apparent trend of increasing with the increase of heating section length ratio, when the heating section is longer than the cooling section, the cooling thermal resistance increases with it apparently; the heat transfer power is the highest when the filling rate is $50 \%$.

\section{Experimental Set-Up}

A schematic layout of the experimental set up is shown in Figure 1.

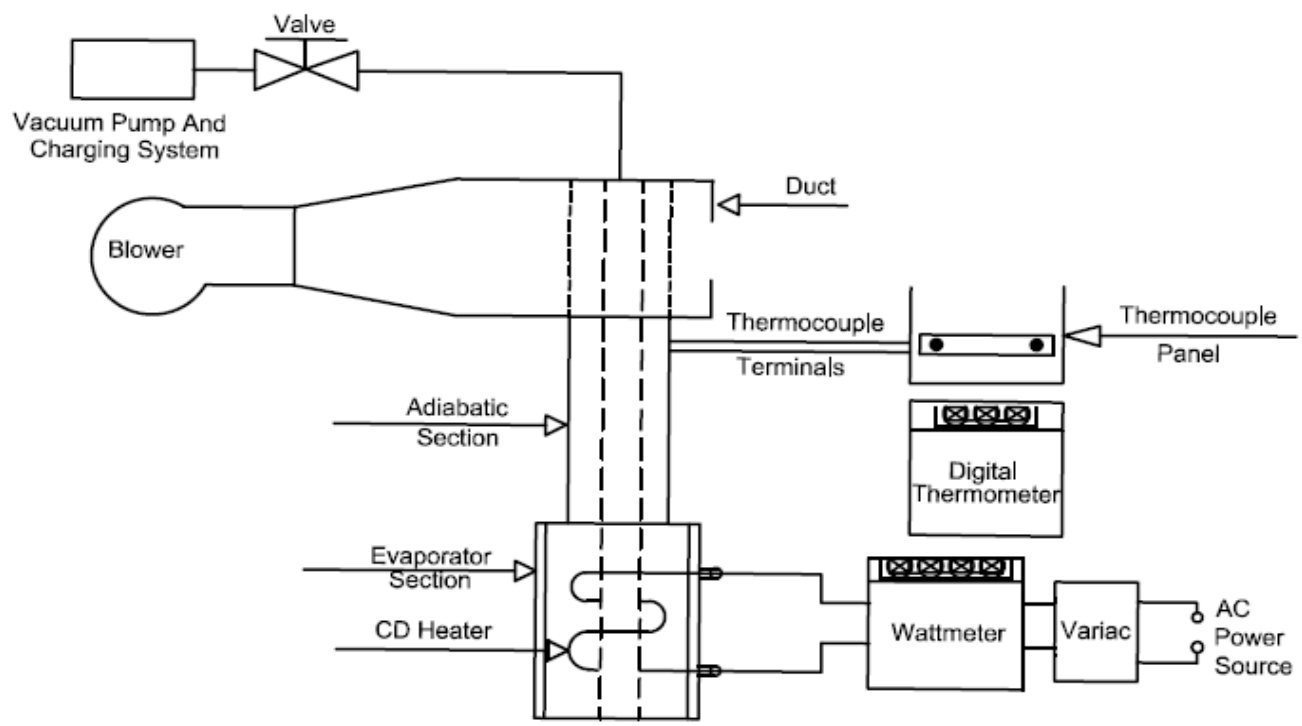

Figure 1. Experimental set up. 
The experimental test consists of the copper/acetone heat pipe, a heater for the evaporator section, duct using blower for heat removal (condenser), temperature measurement equipment, a vapor temperature proper, acetone charging system, and a vacuum pump.

The total length of the pipe is $0.60 \mathrm{~m}$ and copper tube outside diameter is $0.022 \mathrm{~m}$ and the working fluid used in tests is acetone. Through the tests the following parameters were measured: The input power to the heater (evaporator section), inlet and outlet temperature of the air, volume flow rate of the air, volume of working fluid, vapor pressure of pipe working fluid, the heat pipe wall surface temperatures, and vapor temperature of the working fluid.

\section{Results and Discussion}

The experimental were performed for different heat loads.

Figure 2 shows the relation between pipe wall temperature $(\mathrm{T})$ and axial position $(\mathrm{L})$ at the start up along the wrapped screen heat pipe for a given heat load, filling ratio and air velocity.

Figure 3 shows the effect of the air velocity on the vapor temperature (Tv). It is shown that the vapor temperature decreases as air velocity increases. Figure 4 shows the effect of heat load on vapor temperature. It can observed that the vapor temperature increases as the heat load increases. Figure $\mathbf{5}$ shows the relation between pipe wall temperature and axial position at different filling ratios. It indicates that increasing filling ratio decreases the wall temperature.

Figure 6 indicates that the temperature difference decreases as velocity of air increases. From Figure $\mathbf{7}$ it is shown that temperature difference of air increases as heat load increases.

Figure 8 shows the comparison between the experimental results and capillary limit.

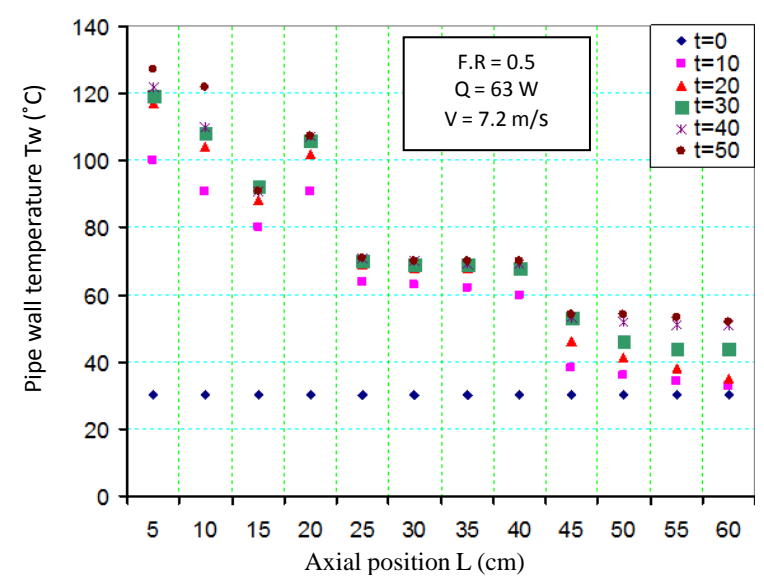

Figure 2. Temperature distribution at the start-up along wrapped screen heat pipe.

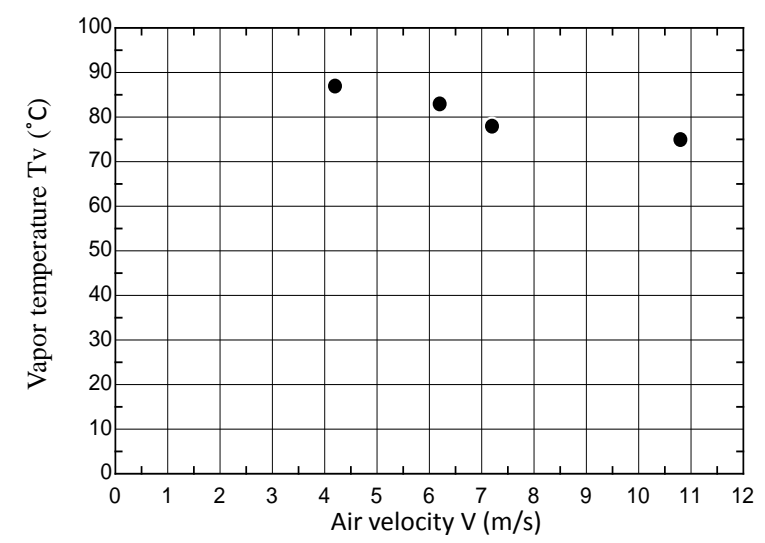

Figure 3. Effect of air velocity on vapor temperature. 


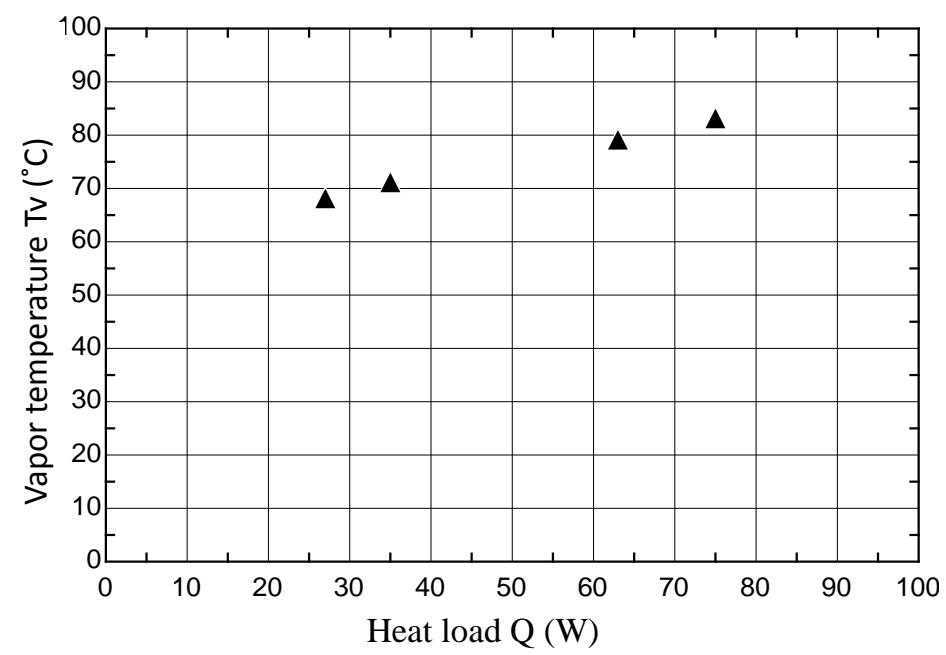

Figure 4. Relation between vapor temperature of working fluid and heat load.

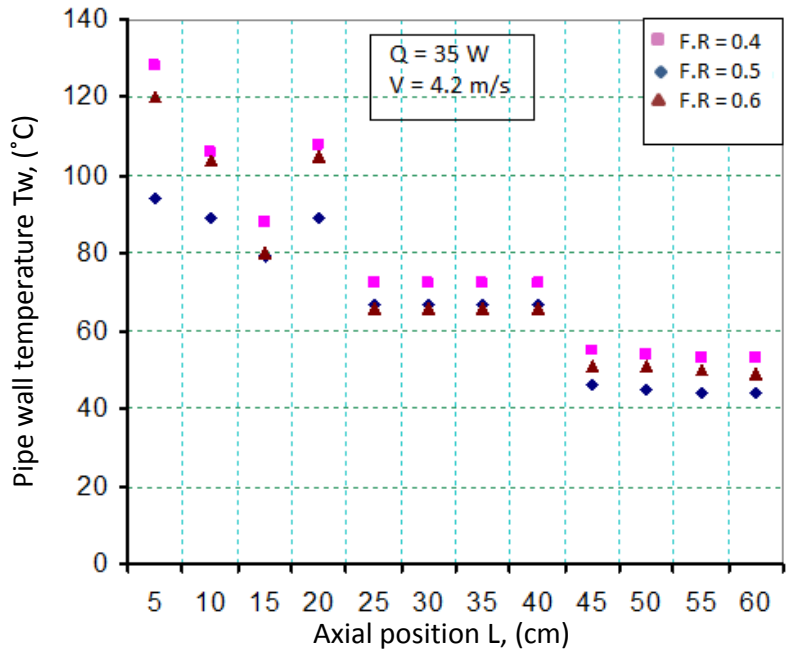

Figure 5. Effect the filling ratio on pipe wall temperature.

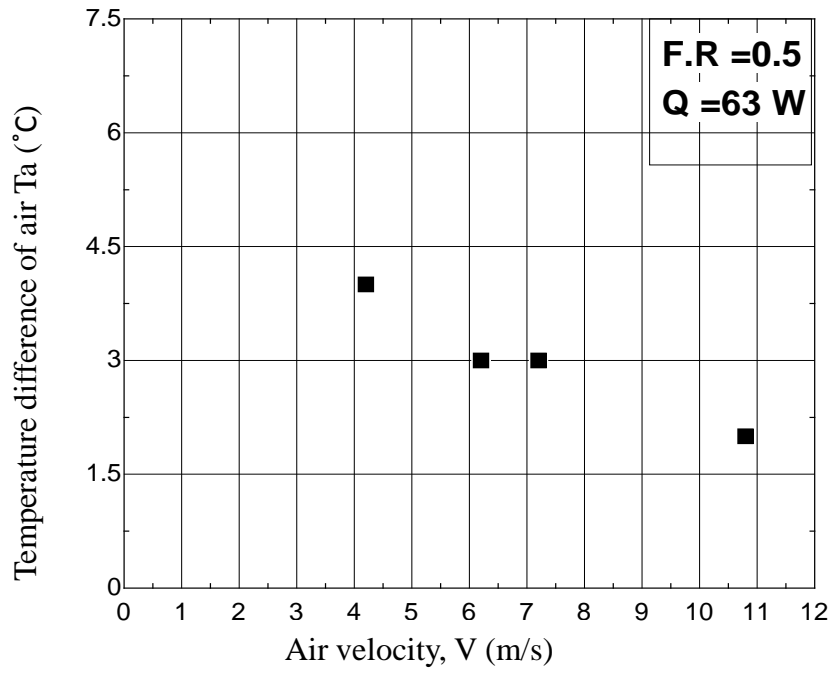

Figure 6. Relation between air velocity and temperature difference of air. 


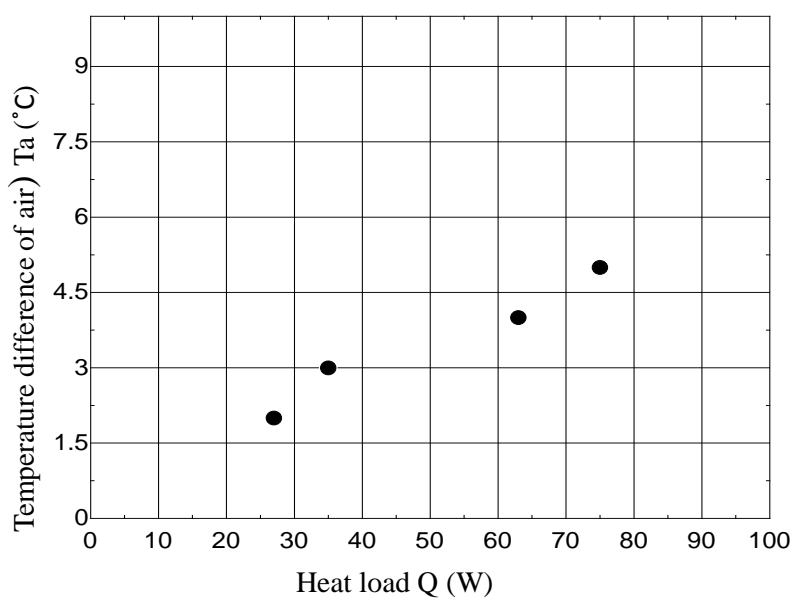

Figure 7. Effect of heat load on temperature difference of air.

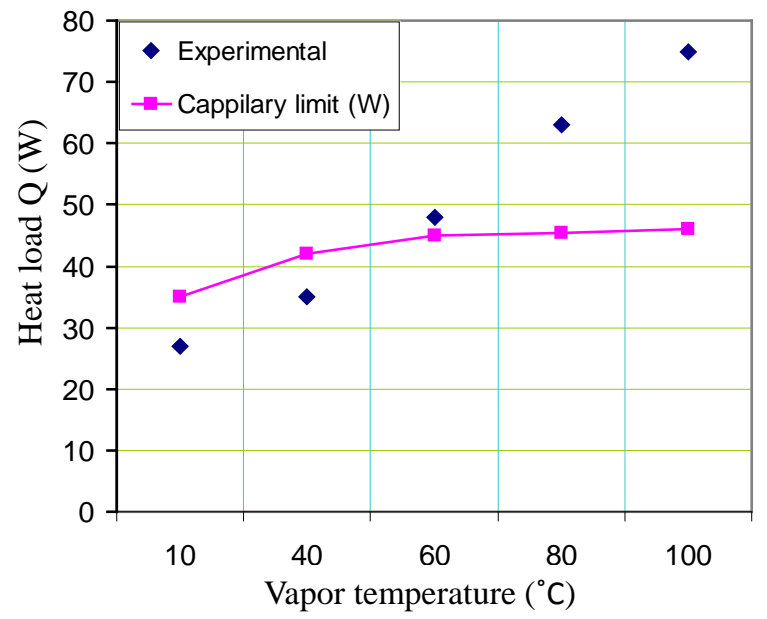

Figure 8. The comparison between the experimental results and capillary limit.

\section{Conclusions}

The utilization and performance of heat pipe was experimentally studied. A copper/acetone heat pipes at different heat loads, volume air velocity were used in this study for wrapped screen heat pipe. The heat pipe is $60 \mathrm{~cm}$ and total length with $2.2 \mathrm{~cm}$ outside diameter, $20 \mathrm{~cm}$ long evaporator section, $20 \mathrm{~cm}$ long condenser section and $20 \mathrm{~cm}$ long adiabatic section. From the present study the following conclusions can be drawn:

1) The comparison between the experimental results and capillary limit [12] as shown in Figure 8 good agreement for vapour temperature range from $15^{\circ} \mathrm{C}-80^{\circ} \mathrm{C}$ a and when the temperature is more than $80^{\circ} \mathrm{C}$ there is difference between the results.

2) The pipe wall temperature (Tw) for a wrapped screen heat pipe has a rapid increase and takes 50 min to reach steady state at $(\mathrm{Q}=63 \mathrm{~W})$.

3) Vapor temperature of working fluid increases as the heat load increases at constant air velocity.

4) The heat load increases the pipe wall temperature increases.

5) Vapor temperature of working fluid slightly decreases as the velocity of air increases.

6) The increase of filling ratio decreases the range of the vapour temperature. This means that increasing of the filling ratio decreases maximum vapour temperature and also decreases the variation in the vapour temperature. The best recorded filling ratio $=0.6$ which has the lowest vapour temperature at highest heat load.

7) The temperature difference of air increases as heat load increases.

8) The maximum temperature difference for these experiments is $5^{\circ} \mathrm{C}$.

9) The maximum heat transport limit for this pipe is $80 \mathrm{~W}$. 


\section{References}

[1] Dinh, K. (2000) Dehumidifier Heat Pipes for Rice Drying and Storage. 6th International Heat Pipe Symposium, Chiang Mai, 5-9 November 2000.

[2] Shafahi, M., Bianco, V., Vafai, K. and Manca, O. (2010) Thermal Performance of Flat-Shaped Heat Pipes Using Nanofluids. International Journal of Heat and Mass Transfer, 53, 1438-1445. http://dx.doi.org/10.1016/j.ijheatmasstransfer.2009.12.007

[3] Meyer, A. and Dobson, R.T. (2006) A Heat Pipe Heat Recovery Heat Exchanger for a Mini-Drier. Journal of Energy in Southern Africa, 17.

[4] Mousa, M.G. (2011) Effect of Nanofluid Concentration on the Performance of Circular Heat Pipe. Ain Shams Engineering Journal, 2, 63-69. http://dx.doi.org/10.1016/j.asej.2011.03.003

[5] Sarmasti Emami, M.R., Noie, S.H. and Khoshnoodh, M. (2008) Effect of Aspect Ratio and Filling Ratio on Thermal Performance of an Inclined Two-Phase Closed. Iranian Journal of Science \& Technology, Transaction B, Engineering, 32, 39-51.

[6] Ong, K.S. and Tong, W.L. (2011) Inclination and Fill Ratio Effects on Water Filled Two-Phase Closed Thermosyphon. 10th IHPS, Taipei, 6-9 November 2011.

[7] Raja Balayanan, S.R., Velmurugan, V., Sudhakaran, R. and Shenbaga Vinayaga Moorthi, N. (2011) Optimization of Thermal Performance of Water to Air Thermosyphon Solar Heat Pipe Heat Exchanger Using Response Surface Methodology. European Journal of Scientific Research, 59, 451-459.

[8] Mirshahi, H. and Rahimi, M. (2009) Experimental Study on the Effect of Heat Loads, Fill Ratio and Extra Volume on Performance of a Partial-Vacuumed Thermosyphon. Iranian Journal of Chemical Engineering, 6.

[9] Firouzfar, E., Soltanieh, M., Noie, S.H. and Saidi, M.H. (2011) Application of Heat Pipe Heat Exchangers in Heating, Ventilation and Air Conditioning (HVAC) Systems. Scientific Research and Essays, 6, 1900-1908.

[10] Lv, F., Yu, G., Zhao, M., Zhang, J.M. and Yang, H.X. (2012) Investigation on Heat Pipe Application in Central AirConditioning Systems. Applied Mechanics and Materials, 170-173, 2546-2549. http://dx.doi.org/10.4028/www.scientific.net/AMM.170-173.2546

[11] Lei, S. (2014) Study of Influence Effect on Heat Transfer Performance of Single-Loop Oscillating Heat Pipe. Applied Mechanics and Materials, 535, 114-118. http://dx.doi.org/10.4028/www.scientific.net/AMM.535.114

[12] Chi, W. (1976) Heat Pipe Theory and Practice. Hemisphere Publishing Corporation, New York. 